\title{
Coming soon to an operating theater near you
}

\author{
Shamus R. Carr, MD, FACS \\ From the Division of Thoracic Surgery, Department of Surgery, University of Maryland School of Medicine, Bal- \\ timore, Md. \\ Disclosures: Author has nothing to disclose with regard to commercial support. \\ Received for publication Sept 8, 2017; accepted for publication Sept 9, 2017; available ahead of print Oct 7, 2017. \\ Address for reprints: Shamus R. Carr, MD, FACS, Division of Thoracic Surgery, University of Maryland School \\ of Medicine, 29 S Greene St, Suite 504, Baltimore, MD 21201 (E-mail: scarr@som.umaryland.edu). \\ J Thorac Cardiovasc Surg 2017;154:2120-1 \\ $0022-5223 / \$ 36.00$ \\ Copyright $($ c 2017 by The American Association for Thoracic Surgery \\ https://doi.org/10.1016/j.jtcvs.2017.09.041
}

As the use of computed tomographic (CT) scans becomes more ubiquitous, and lung cancer screening programs grow and evolve, more pulmonary nodules are being found then ever before. ${ }^{1}$ As serial imaging demonstrates evolution and growth of a nodule, certain nodules, such as ground glass opacities, can prove a vexing problem to locate, palpate, and then biopsy, especially when they are not immediately adjacent to the visceral pleura. Because of this exact issue, various localization techniques, such as hook wire, fiducial markers, and navigational bronchoscopy with injection of methylene blue, have all been reported and published, with varying degrees of success. ${ }^{2-4}$

Although the origins of 3-dimensional (3D) printing originate back to the early $1980 \mathrm{~s}$, it has only more recently made its way into various fields, including surgery. Since 2011, there has been an exponential increase in articles published addressing the clinical applications across all surgical fields. ${ }^{5}$ Cardiothoracic surgery was an early adoption and use specialty, but it is mainly cardiac, and not thoracic, surgery, that has used this technology, until now.

In this issue of the Journal, Zhang and colleagues ${ }^{6}$ report a pilot study that asked whether an individualized 3D printed template would be able to aid accurately and safely in video-assisted thoracoscopic surgical needle identification and resection of a ground glass opacity. This was accomplished by using 3D printing technology to construct a template from the CT scan of a patient. The template was then placed on the patient, and a localizing wire was placed through the biopsy site to a predetermined depth. The accuracy and precision of the needle was then confirmed with a CT scan. The patient was then taken to the operating room for video-assisted thoracoscopic surgical wedge resection of the localized nodule. All nodules in the 16 patients were resected with the aid of the needle localization $3 \mathrm{D}$ templates. The strength of study is that these ground glass opacity nodules on average were smaller than $20 \mathrm{~mm}$ and at least $10 \mathrm{~mm}$ from the pleural surface. These are exactly the nodules that routinely give thoracic surgeons fits. Caution needs to be exercised, however, because this was a pilot study. The well-understood limitations of a pilot

\section{References} 2015;192:1208-14.

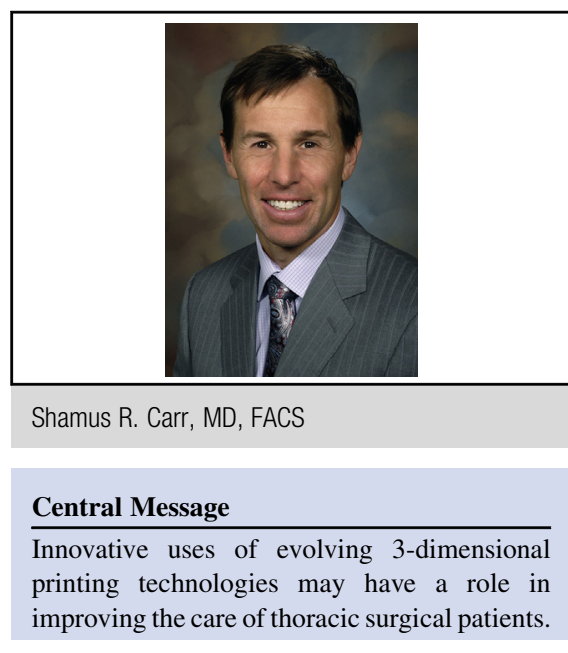

See Article page 2113.

study are evident. A point that needs to be kept in mind is the body mass index of the patients. The average body mass index for this study was $22.7 \mathrm{~kg} / \mathrm{m}^{2}$, a value that most surgeons from Western countries would envy. The average body mass index in the United States, as reported by the US Centers for Disease Control and Prevention, is $28.5 \mathrm{~kg} / \mathrm{m}^{2}$. Could the application to larger Western patients decrease the technique's success?

Just as some inventions end up with unexpected positive results, the benefits for this technology may extend well beyond facilitating finding the nodule. A median time of only 13 minutes to localize the nodule would likely translate to shorter operations for patients, thus decreasing time under anesthesia and saving money-especially if the template can be made from the original scan so that additional scans on the day of surgery are not required. This then brings up the concern of the cost for the printing of the 3D template. It has been estimated that saving $10 \mathrm{mi}-$ nutes in the operating room is equivalent to 1 hour of work spent in the production of a 3D-printed object. ${ }^{7}$ Having a nodule already localized and not requiring palpation likely will save significant time, and thus money.

This novel use of 3D technology to aid in the localization of pulmonary nodules could save time and money. It may be exactly what thoracic surgeons did not know they actually need. Now, on with the show.

1. Gould MK, Tang T, Liu IL, Lee J, Zheng C, Danforth KN, et al. Recent trends in the identification of incidental pulmonary nodules. Am J Respir Crit Care Med. 
2. Gruber-Rouh T, Naguib NN, Kleine P, Vogl TJ, Jacobi V, Beeres M, et al. CTguided hook-wire localisation prior to video-assisted thoracoscopic surgery of pulmonary lesions. Clin Radiol. 2017;72:898.e7-11.

3. Sancheti MS, Lee R, Ahmed SU, Pickens A, Fernandez FG, Small WC, et al Percutaneous fiducial localization for thoracoscopic wedge resection of small pulmonary nodules. Ann Thorac Surg. 2014;97:1914-8; discussion 1919.

4. Luo K, Lin Y, Lin X, Yu X, Wen J, Xi K, et al. Localization of peripheral pulmonary lesions to aid surgical resection: a novel approach for electromagnetic navigation bronchoscopic dye marking. Eur J Cardiothorac Surg. 2017;52:516-21.
5. Hoang D, Perrault D, Stevanovic M, Ghiassi A. Surgical applications of threedimensional printing: a review of the current literature \& how to get started. Ann Transl Med. 2016;4:456.

6. Zhang L, Li M, Li Z, Kedeer X, Wang L, Fan Z, et al. Three-dimensional printing of navigational template in localization of pulmonary nodule: a pilot study. $J$ Thorac Cardiovasc Surg. 2017;154:2113-9.e7.

7. Martelli N, Serrano C, van den Brink H, Pineau J, Prognon P, Borget I, et al. Advantages and disadvantages of 3-dimensional printing in surgery: a systematic review. Surgery. 2016;159:1485-500. 